\title{
8
}
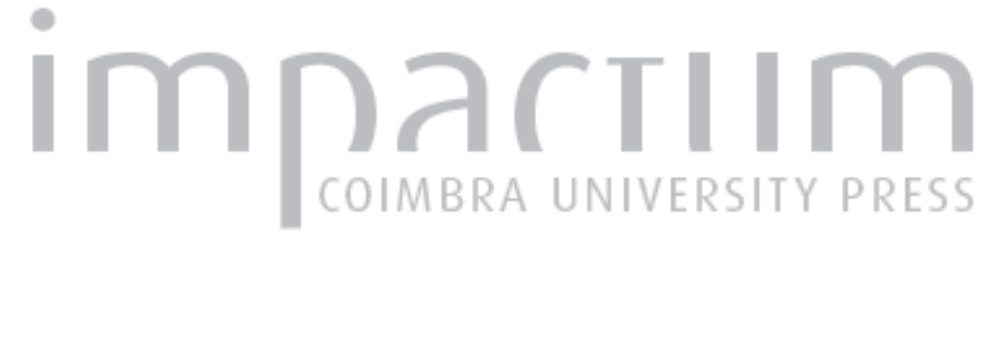

\section{[Recensão a] JOSÉ ORTEGA Y GASSET, JOSÉ GAOS, JOAQUÍN XIRAU, LEOPOLDOEULOGIO \\ PALÁCIOS, AGUSTÍN SERRANO DE HARO, Cuerpo Vivido}

\author{
Autor(es): $\quad$ Umbelino, Luís António
}

Publicado por: Faculdade de Letras da Universidade de Coimbra, Instituto de Estudos

URL

persistente: URI:http://hdl.handle.net/10316.2/29618

DOI: $\quad$ DOI:http://dx.doi.org/10.14195/0872-0851_39_13

Accessed : $\quad$ 26-Apr-2023 15:09:35

A navegação consulta e descarregamento dos títulos inseridos nas Bibliotecas Digitais UC Digitalis, UC Pombalina e UC Impactum, pressupõem a aceitação plena e sem reservas dos Termos e Condições de Uso destas Bibliotecas Digitais, disponíveis em https://digitalis.uc.pt/pt-pt/termos.

Conforme exposto nos referidos Termos e Condições de Uso, o descarregamento de títulos de acesso restrito requer uma licença válida de autorização devendo o utilizador aceder ao(s) documento(s) a partir de um endereço de IP da instituição detentora da supramencionada licença.

Ao utilizador é apenas permitido o descarregamento para uso pessoal, pelo que o emprego do(s) título(s) descarregado(s) para outro fim, designadamente comercial, carece de autorização do respetivo autor ou editor da obra.

Na medida em que todas as obras da UC Digitalis se encontram protegidas pelo Código do Direito de Autor e Direitos Conexos e demais legislação aplicável, toda a cópia, parcial ou total, deste documento, nos casos em que é legalmente admitida, deverá conter ou fazer-se acompanhar por este aviso. 


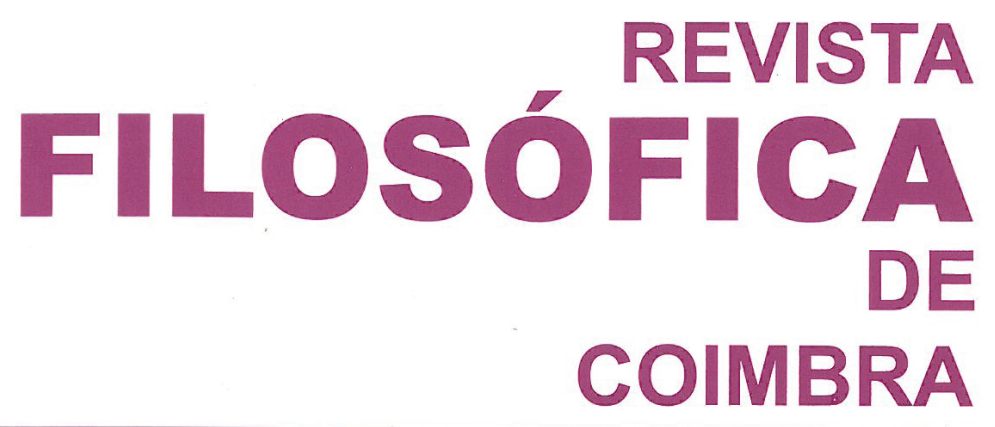

vol. 20 - número 39 - março 2011

vol. 20 - número 39 - março 2011

Fundação Eng. António de Almeida

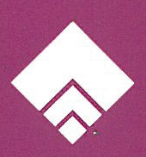


tradição interpretativa bem como a interpelação à reflexão sobre os antagonismos do nosso tempo. A publicação é bem sucedida explorando uma grande diversidade de temáticas pertinentes da Antropologia Filosófica contemporânea, logrando ir além do saber meramente edificante criticado por Hegel.

Cláudio Alexandre S. Carvalho

JOSÉ ORTEGA Y GASSET, JOSÉ GAOS, JOAQUÍN XIRAU, LEOPOLDOEULOGIO PALÁCIOS, AGUSTÍN SERRANO DE HARO, Cuerpo Vivido, Encuentro, Madrid, 2010.

O leitor competente de filosofia que cultive o gosto pelo espírito fino mas vigoroso, encontrará na publicação em apreço um extraordinário colóquio filosófico que, atravessando o séc. XX e virando o milénio, vem surpreender-nos com a sua inequívoca actualidade e inegável interesse. Reunidos em torno do tema do corpo e da corporeidade, encontraremos neste livro cinco vozes espanholas ilustres, cujos textos foram em boa hora reunidos por Agustín Serrano de Haro do Instituto de Filosofia do CSIC e conhecido presidente da Sociedade Espanhola de Fenomenologia.

O primeiro desses textos é de Ortega Y Gasset e tem por título "Vitalidad, alma e espírito" (pp. 15-52). Tendo a sua origem numa conferência de 1925, o admirável ensaio chama renovadamente a pensar a partir da evidência de que são diversos e heterodoxos os modos de aparecer do corpo: podemos considerá-lo a partir de fora, mas também a partir de "dentro" (cf. p. 21), havendo então lugar a considerá-lo a partir de um ponto de vista que permita mostrar em que medida o sei "meu". Nesta via de análise, que será a da tematização do "intracorpo" (pp.20 e ss.), traça Ortega uma verdadeira descrição fenomenológica do corpo vivido ou corpo próprio, que o conduz a meditar todo um conjunto de experiências, tão familiares que porventura se ignoram, onde se surpreendem traços específicos da nossa corporeidade complexa. É neste sentido que o pensador madrileno nos conduz ao longo de uma análise rica de detalhes, e cujos pontos centrais se podem elencar seguindo as derradeiras divisões do próprio texto: consideração do "espírito e da alma", ou "fundo de vitalidade" que nutre "todo o resto da nossa pessoa" (pp.27 e ss.), ponderação da estrutura tripartida da nossa intimidade em três zonas - vitalidade, alma e espírito - que nos conduzem à trilogia conceptual de "ciência, orgia e alma" (pp. 33 e ss.), estudo da "alma como excentricidade" (pp.37 e ss), esboço uma "geometria sentimental" (pp. 40 e ss.) e, finalmente, ensaio de uma nova "caracteriologia" (pp. 43 e ss).

Segue-se um texto de José Gaos sobre "a carícia" (53-85), trabalho inicialmente incluído na obra Dos exclusivas del hombre: la mano y el tiempo, publicada em 1945 no desterro mexicano do discípulo de Ortega. No texto de apresentação Agustín Serrano de Haro reputa a análise do acto de acariciar e do 
fenómeno da carícia aí contido como "memorável", mais afirmando tratar-se de uma "jóia da descrição fenomenológica" (p. 9). Pela nossa parte, não regateamos tais qualificativos. De facto, o texto de Gaos impressiona pela finura e pela minúcia do exame, pela progressão cuidada que se esforça por assentar cada nova aquisição teórica nas lentas conquistas pacientemente já estabelecidas. Surpreende ainda neste texto - facto igualmente bem assinalado por Serrano de Haro (p. 9) - todo um conjunto de vigorosas propostas que se aproximam, e mesmo antecipam, teses que encontramos em algumas das passagens mais célebres da filosofia merleau-pontyana; de facto, a tentativa de superação dos naturalismos e idealismos espiritualistas, por um lado e, por outro, a descoberta do carácter carnal da carícia (veja-se, por exemplo, p. 81) não deixarão indiferentes os cultores da filosofia de Merleau-Ponty e, em geral, os estudiosos da denominada fenomenologia francesa.

O terceiro trabalho incluído no livro em apreço é da autoria do catalão Joaquín Xirau e intitula-se: "Presencia del Cuerpo" (pp. 87-98). Tendo sido publicado pela primeira vez em 1946, o enorme interesse e importância deste texto pode ser facilmente medido através dos diálogos e intertextualidades que oferece ao leitor competente de filosofia. Destacaríamos três momentos, a nosso ver particularmente relevantes e ilustrativos das possibilidades que este trabalho alberga: desde logo, a distinção entre "corpo exterior, o dos médicos, dos biólogos e dos físicos", corpo que em rigor não posso dizer ser o "meu corpo", e o "corpo interior, subjectivo no qual e pelo qual vivo" (p.90) - tal distinção, como é evidentemente, não está longe da célebre destrinça de Husserl entre Körper e Leib, permitindo igualmente uma leitura comparada com a distinção orteguiana entre corpo exterior e "intracorpo"; em segundo lugar, não pudemos deixar de notar que Xirau, ao referir-se à "comédia ou tragédia" que é o "meu drama interior" (p. 90), traz à memória a afirmação similar de P. Ricoeur que, desde os seus trabalhos fenomenológicos, vislumbrou o ritmo dramático do existir humano marcado por uma corporeidade irrevogável; finalmente, e muito em particular, interessou-nos a afirmação de que "a resistência" (p. 88, nomeadamente) é um dos "aspectos essenciais através dos quais posso dizer que o corpo é meu e que sou eu nele e por ele" (p. 88) - tal tese, deve notar-se, foi auroralmente estabelecida pelo filósofo francês Maine de Biran (1766-1824), a quem se deve, defendemos, um dos primeiros projectos sistemáticos de elaboração de uma filosofia do corpo próprio. Na referência de Xirau à resistência, atrevemo-nos, então, a ler a confirmação do quanto o projecto biraniano (cuja influência "subterrânea" sobre o pensamento contemporâneo não pode ser negada, apesar de quase sempre ser esquecida) merece, a nosso ver, continuar a ser estudado.

Consideremos agora o quarto ensaio apresentado aqui. Trata-se de "El Rostro y su Anulacíon", texto publicado pela primeira vez em 1965 e cujo autor é Leopoldo-Eulogio Palácios. O tema do rosto é aqui tratado ao longo de linhas densas mas luminosas. Nestas pressente-se a influência mais ou menos difusa de Kant e de Schopenhauer, mas o que através delas nos interpela é, sem dúvida, 
um pensamento original. Merece, pois, toda a atenção este texto que viaja entre o rosto, marca distintiva da humanidade, e a sua anulação. Neste sentido, podemos dizer que o trabalho em apreço se organiza em dois grandes momentos: numa primeira parte, considera-se "a cara do homem" (pp. 99-100), "a necessidade do rosto para a vida humana" (101-107), o "rosto falante ou "bico"” (106-107), "o meu rosto e o rosto dos outros" (pp. 107-109); e numa segunda parte analisa-se a anulação do rosto pelo "véu" e pela "máscara" (pp. 110-112), a sua obliteração na "efígie" (pp. 113-117) e a estranha negociação que, connosco próprios, mantemos ao longo da vida quando confrontados com a "consciência" do que o rosto é, em grande parte, ilusório (pp. 117-122).

$\mathrm{O}$ volume em apreço encerra-se da melhor maneira com um texto, de raro interesse, do seu editor, o único dos cinco autores que "vive neste século". Agustín Serrano de Haro publica aqui um trabalho inédito com o título "Atención y Dolor. Análisis Fenomenológico" que se propõe - com inegável talento e vigor fenomenológicos - pensar a "peculiar relação que as vivências da dor mantêm com o factor atencional, ou mais especificamente com a atenção" (p. 123). Neste sentido, o grosso do trabalho pretende "esboçar (...) uma ordenação descritiva das experiências de dor física", desde "o extremo da dor aguda absorvente, para a qual toda a atenção aprece pouca, e o extremo oposto, no caso a dor insensível inadvertida, que se esfuma da consciência e para a qual, pelos vistos, a mais pequena atenção chega e sobra" (p. 130). Como esclarece o autor, tal descrição não tem, no entanto, como escopo, a composição de uma mera taxionomia de tipo empírico que ordenasse patologias, graus de dor, ou quaisquer indicadores clínicos afins; do que aqui se trata é, outrossim, de um ensaio de "clarificação fenomenológica que, como tal tenha verdadeiro alcance ontológico" (131). Os resultados de tal investigação, aportados num estilo cativante, rico de exemplos, mas rigoroso e sem cedências à facilidade, parecem-nos representar um contributo de grande importância, que não deixará de interessar a todos quantos, nos mais diversos campos disciplinares, se interessam pelos temas da atenção e da dor física - cuja força pode escandalosamente interromper a vigência da consciência, como só uma potência "obtusa" (p.161) que seca o sentido, é capaz.

Pelo exposto, consideramos o texto em consideração, uma pequena preciosidade: ao mesmo tempo que nos oferece um quadro inspirador da filosofia espanhola, ao mesmo tempo que nos disponibiliza descrições de grande alcance sobre aspectos precisos da nossa corporeidade - tão familiares como o andar ou o acariciar, tão próximos como o encontro (e desencontro) com o rosto - constitui-se ainda como documento de inegável relevância filosófica, sendo, certamente, de leitura obrigatória para todos quantos trabalham no âmbito de uma filosofia do corpo e da corporeidade.

Luís António Umbelino 